1184 A SYSTEMATIC REVIEW ON MEASUREMENT TECHNIQUES OF WORKERS' EXPOSURE TO NANOMATERIALS IN LOW- AND MIDDLE- INCOME COUNTRIES

Fabio Boccuni* ${ }^{\star}$ Diana Gagliardi, Riccardo Ferrante, Bruna Maria Rondinone, Sergio lavicoli. INAIL - Department of Occupational and Environmental Medicine, Epidemiology and Hygiene

\subsection{6/oemed-2018-ICOHabstracts.835}

Introduction Nanotechnology expresses great potential as enabling technology but there are still uncertainties about the health risks for workers potentially exposed to nano-objects and their agglomerates and aggregates (NOAA). Different methodological approaches to measure airborne NOAA in the workplace have been proposed. This study finalised a systematic review on this theme with the aim to identify techniques of exposure measurement to be recommended even in contexts with low resources, such as Low- and Middle- Income (LMI) countries.

Materials and methods We collected scientific papers reporting techniques of NOAA exposure measurements in the workplace and we summarised the data for each eligible technique according to PRISMA guidelines; then we rated the quality of evidence following an adapted GRADE approach.

Results We found 69 eligible studies to be included in qualitative synthesis: the majority of studies reported a moderate quality and only 2 studies demonstrated the use of a high quality exposure measurement technique. The review demonstrates that a basic exposure measurement, i.e. evidence for the presence or absence of NOAA in the workplace air, can be achieved with moderate (40 techniques) to high quality (2 techniques); 13 of these techniques are defined as comprehensive, since they allow also the quantification of NOAA in the workplace.

Conclusions This systematic review allowed identifying criteria for a reliable measurement of exposure to NOAA to be recommended in LMI countries. The findings of the study defined a list of requirements that must be fulfilled by an effective measurement technique (either basic or comprehensive), and highlighted the main weaknesses that need to be tackled for an effective affordability evaluation.

\section{OCCUPATIONAL NOISE INDUCED HEARING LOSS AMONG TANZANIAN METAL INDUSTRY WORKERS}

${ }^{1}$ Alexander M Tungu* ${ }^{*}{ }^{1,2}$ Israel P Nyarubeli, ${ }^{2}$ Magne Bråtveit, ${ }^{2}$ Erlend Sunde, ${ }^{3}$ Akwilina Kayumba, ${ }^{2}$ Bente E Moen. 'Muhimbili University of Health and Allied Sciences, Dar es Salaam, Tanzania; ${ }^{2}$ Centre for international Health, University of Bergen, Bergen, Norway; ${ }^{3}$ Occupational Safety and Health Authority (OSHA), Tanzania

\subsection{6/oemed-2018-ICOHabstracts.836}

Introduction Noise induced hearing loss (NIHL) is apreventable disease. However, the global burden of NIHL is increasing; especially in developing countries. The prevalence of NIHL among metal industry workers in Sub Saharan countries including Tanzania is not well documented.

Methods This study was conducted among male metal industry workers (Exposed, $\mathrm{n}=226$ ) and Public Primary School teachers (Controls, $\mathrm{n}=110$ ) between June 2016 and June 2017, in Dar es Salaam. The exposed were from four metal industries (Factory $A, n=65 ; B, n=45 ; C, n=53 ; D, n=63)$. Hearing thresholds at $0.5,1,2,3,4,6$ and $8 \mathrm{KHz}$ were examined using Interacoustic AD 226 audiometer. NIHL was defined as hearing threshold levels $>25 \mathrm{~dB}$ in either ear at 3,4 and $6 \mathrm{KHz}$. The WHO classification of hearing loss was used.

Results The prevalence of NIHL among exposed was 50\% and $47 \%$ in the right and left ear, respectively. The highest prevalence was found in factory $\mathrm{B}(71 \%$ and $62 \%)$, followed by $\mathrm{D}(48 \%$ and $54 \%), \mathrm{A}(48 \%$ and $48 \%)$, and the lowest in factory $\mathrm{C}(37 \%$ and $25 \%)$ in the right and left ear, respectively. The proportion of mild, moderate and severe NIHL in the right and left ear was $80 \%$ and $79 \%, 20 \%$ and $18 \%, 0 \%$ and $2 \%$, respectively.

Among controls, the prevalence of NIHL was $31 \%$ and $28 \%$ in the right and left ear, respectively. The proportion of mild, moderate, severe NIHL in the right and left ear was $86 \%$ and $76,11 \%$ and $15 \%, 3 \%$ and $0 \%$, respectively. Nine percent of the controls had profound NIHL in the left ear and none among exposed.

Discussion We found high prevalence of NIHL among Tanzanian metal industry workers. Further studies on noise exposure and the determinants for reduced hearing are needed. Establishment of a hearing conservation program in the metal industries seems to be important.

\section{WORKPLACE EXPOSURE PROBLEMS DETERMINED IN CLEANING PROFESSIONALS WORKING IN IZMIR ANTALYA AND BURSA PUBLIC HEALTH DIRECTORIES}

${ }^{1}$ Serap Gökmen, ${ }^{1}$ Naile Ertürk, ${ }^{2}$ Yasemin Uçar, ${ }^{3}$ Deniz Ilknur Ardali, ${ }^{4}$ Hikmet Arif Çimrin, ${ }^{5}$ Frederieke Schaafsma, ${ }^{6}$ Mustafa Kemal Başarali, ${ }^{6}$ Ahmet Özlü. ${ }^{1}$ Public Health Directorate of Izmir, Turkey; ${ }^{2}$ Public Health Directorate of Antalya, Turkey; ${ }^{3}$ Public Health Directorate of Bursa, Turkey; ${ }^{4}$ 9th Semptember University Izmir Turkey; ${ }^{5}$ Dept. of Public and Occupational Health, VU University Medical Centre, Amsterdam Public Health research institute, Netherland; ${ }^{6}$ Public Health Institution of Turkey

\subsection{6/oemed-2018-ICOHabstracts.837}

Introduction Physical, chemical and biological risk factors exist in workplaces of cleaning professionals. These risk factors at work may cause respiratory, skin, and musculoskeletal health problems for these workers. The prevalence of these health problems caused by occupational risk factors such as exposure to chemicals in cleaning products and physical strain in the workplace of cleaning professionals are not yet fully known in Turkey.

For this reason, the objective was to assess the extent of workplace exposure to occupational risk factors for cleaning professionals of 1zmir, Antalya and Bursa Public Health Directorates (including subcontractors).

Methods We plan a cross sectional study using a questionnaire on socio-demographic characteristics, risk factors at work, work history, health history, health status, exposures,European Community Respiratory Health Survey II(ECHRS II) questionnaire, Nordic Occupational Skin Questionnaire and the Nordic Musculoskeletal Questionnaire using a face-to-face interview method. The interviews will be performed by trained occupational health and safety specialists from the Public Health Directorates of 1zmir, Antalya and Bursa Turkey. 
The study proposal has been approved by 9thSeptember University Ethical Committee. Workers will be asked for informed consent before the survey.

Result We will include 370 cleaning professionals in the study. The prevalence of respiratory, skin and musculoskeletal symptoms will be determined, stratified for different cleaning professionals and their socio-demographic variables. We expect all results in October 2017.

Discussion The main outcome is the estimated prevalence of work-related disorders in cleaning professionals and associated occupational risk factors in Turkey. We will also analyse the effect of these disorders on the related prevalence of disability in work and daily life. Based on the results, interventions for prevention of will be recommended.

\section{THE DEVELOPMENT OF OCCUPATIONAL HEALTH AND SAFETY IN THE UNIVERSITY LABORATORIES IN TURKEY}

${ }^{1}$ A Bolukbas*, ${ }^{2} \mathrm{OA}$ Ergor. 'Dokuz Eylul University, Faculty of Engineering, Environmental Engineering, Izmir, Turkey; ${ }^{2}$ Dokuz Eylul University, Faculty of Medicine, Department of Public Health, Izmir, Turkey

\subsection{6/oemed-2018-ICOHabstracts.838}

Introduction The significant obligations have become valid by the change in the legislation with the Occupational Health and Safety Law in Turkey. Thereafter, besides private sector, public institutions have to establish and apply occupational health and safety systems. Therefore, occupational health and safety systems have been started to establish in the universities including the university laboratories which include several potential hazards such as chemical substances, biological materials and electrical systems. The aim of the study is to observe the development of occupational health and safety in the universities.

Methods The study has been conducted in a laboratory in Environmental Engineering Department of Dokuz Eylul University. The risk assessment method based on $5 \times 5$ matrices and Failure Mode and Effect (FMEA) have been used. The 5 $\times 5$ matrix risk assessment was modified with respect to daily dosage for workers and taken measurements like engineering, administrative and personal. FMEA has been selected due to the detectability factor in order to observe the awareness of the workers.

Results The $5 \times 5$ matrix risk assessment evaluates existing situation by considering the working hours of the workers with hazard and the positive effects of precautions. FMEA evaluates the risks as there is no precautions and the workers are exposed to the hazard during all shift. As a result of the risk assessments, to prevent the chemical, biological, physical, ergonomic, psychosocial and working environment risks precautions were taken with respect to the regulation; however, they aren't adequate. The system was established but is not completely and properly worked.

Conclusion To conclude, education and drill have to be conducted and emergency plans must be prepared. Working processes with chemicals and biological samples have to be defined and the workers have to be trained. Laboratories and storages have to be organised according to state of the art technologies. Preventive health services have to be provided for workers. The occupational health and safety system in the laboratories has to be improved for efficient protection.
126

BASELINE URINARY FINDINGS IN YOUNG ADULTS AT RISK OF CHRONIC KIDNEY DISEASE OF UNDETERMINED CAUSE IN NORTHWESTERN NICARAGUA

${ }^{1}$ ET Smpokou*, ${ }^{1} B$ La Rosa Garcia, ${ }^{2}$ Le Blond, ${ }^{3}$ J Glaser, ${ }^{4} \mathrm{~A}$ Camacho, ${ }^{5} \mathrm{D}$ Faber, ${ }^{4}$ A Aragón, ${ }^{1} \mathrm{~J}$ Norman, ${ }^{6} \mathrm{~N}$ Pearce, ${ }^{6} \mathrm{D}$ Nitsch, ${ }^{1,4,6} \mathrm{M}$ González, ${ }^{1} \mathrm{~B}$ Caplin, ${ }^{7} \mathrm{~J}$ Morton. ${ }^{1}$ Centre for Nephrology, University College London (UCL), London, UK; ${ }^{2}$ Royal School of Mines, Imperial College London, London, UK; ${ }^{3}$ La Isla Network, Chicago, Illinois, USA; ${ }^{4}$ Research Centre on Health, Work and Environment, National Autonomous University of Nicaragua, León, Nicaragua; ${ }^{5}$ La Isla Foundation, León, Nicaragua; ${ }^{6}$ Non-Communicable Disease Epidemiology, London School of Hygiene and Tropical Medicine, London, UK; ${ }^{7}$ Health and Safety Laboratory, Health and Safety Executive, Harpur Hill, Buxton, UK

\subsection{6/oemed-2018-ICOHabstracts.839}

Introduction There is an epidemic of Chronic Kidney Disease of undetermined cause $(\mathrm{CKDu})$ in Central America causing the death of tens of thousands of agricultural workers. We have undertaken a community-based cohort study to identify factors associated with loss of kidney function in young adults at high risk of CKDu. The aim of this analysis was to characterise the associations between urinary findings at baseline and loss of kidney function (eGFR) over the follow-up period.

Methods We analysed urine samples from 350 apparently healthy men and women (ratio 3:1) from 9 communities in northwest Nicaragua. Semi-quantitative analysis using urine test strips (Siemens Multistix10 SG Reagent Strips) was performed on stored frozen samples. Albumin and creatinine levels were quantified using bromocresol green and Jaffe methods, respectively. Metals were analysed by ICP-Mass Spectrometry. Test strip findings were compared between the group with more stable function and the group with declining eGFR. Linear regression was used to investigate the associations between urinary metal concentrations and change in eGFR.

Results The majority of study participants had normal test strip results however there was an association between increased proteinuria (but without evidence of elevated albumin) in the declining group in comparison to the stable group $(\mathrm{p}=0.03)$. Aluminium and cadmium levels were above accepted limits compared to the general population, but no association with loss of eGFR was found.

Discussion A urine strip test is unlikely to be useful in identifying those with early CKDu. The positive urine strip test for protein in the absence of albuminuria in a proportion of those with declining kidney function likely indicates the presence of other proteins of tubular origin. Our data suggest high levels of overall exposure to aluminium and cadmium but do not suggest these metals have a causal role in loss of kidney function.

\section{PRELIMINARY STUDY OF THE PREVENTION CULTURE IN COMPANIES HAVING MORE THAN 100 WORKERS IN CÔTE D'IVOIRE}

${ }^{1} \mathrm{AJ}$ Eba* 1,2BY Yeboué-Kouamé, 1,3JH Kouadio, ${ }^{2} \mathrm{JS}$ Bonny. ${ }^{1}$ Département Santé au Travail, Laboratoire de (Bio) Toxicologie et Hygiène Industrielle, DPPSST, CNPS 01 B.P. 317 Abidjan, Côte d'Ivoire; ${ }^{2}$ Département de Médecine du Travail, Médecine légale et de Toxicologie, UFR SMA, Université FHB, BPV 166 Abidjan, Côte d'Ivoire; 'Département de Biochimie Microbiologie, UFR Agroforesterie, Université JLG, BP 150 Daloa, Côte d'Ivoire

\subsection{6/oemed-2018-ICOHabstracts.840}

Introduction Safety and health culture is about the perception shared by the organisation's members towards safety and the effort to maintain the safety and health level in the 